\title{
MJN EFFECT OF JAW RELAXATION TECHNIQUE ON LOW BACK PAIN AND SELECTED VITAL SIGNS AMONG NURSING STAFF: A RANDOMIZED CONTROLLED TRIAL
}

\author{
Naglaa Fawzy, Dalia Salah EI-Deen* \\ Medical Surgical Nursing Department, Faculty of Nursing, Cairo University, Cairo, Egypt \\ *Corresponding Author's Email: dalia_elsedawy@hotmail.com
}

\begin{abstract}
Background: Nurses are repeatedly exposed to many forms of occupational hazards such as low back pain while doing their jobs. Aim: The aim of this study was to examine the effect of jaw relaxation technique on low back pain and selected vital signs among nursing staff. Methodology: A randomized control clinical trial study design was utilized. A randomized sample composed of 60 adult male and female nurses working in both medical and surgical specialty departments in a governmental hospital in Egypt were recruited. Three tools were utilized for data collection: I. Demographic- and Work-Related Data, II. Numeric Pain rating scale (NPRS) and III. Medical related data. Results: There was a statistically significant difference in mean systolic and diastolic blood pressure, heart and respiratory rates, as well as low back pain score among nurses before and after practicing Jaw relaxation technique. While, no statistically significant difference was found in low back pain mean score and selected vital signs between post intervention 1\& 2. Conclusion: Low back pain mean score improved among nurses after implementation of the jaw relaxation technique. Recommendation: Jaw relaxation technique is recommended to be endorsed as an adjuvant non-pharmacological pain management and coping strategy.
\end{abstract}

Keywords: Jaw Relaxation Technique, Low Back Pain, Vital Signs, Nursing Staff

\section{INTRODUCTION}

Musculoskeletal disorders are considered the main cause of injury among hospital workers. Low back pain is a common health problem among individuals worldwide and has a lifetime prevalence ranged from $60 \%$ to $90 \%$. It always affects most of the working population in both developed and developing countries (Merskey \& Bogduk, 2018), resulting in disability in a significant number of individuals (Hanoch \& Elavarasi, 2016). Literature review showed significant association between back pain and disability, and its effect on activities of daily living have been also documented.

Low back pain (LBP) studies are of great importance in occupational health, because this type of pain causes severe personal discomfort, disability and impairment in quality of life. In addition, back pain has economic consequences because of increased costs, decreased productivity, frequent sick leave, as well as inability to perform the assigned tasks (Aminta et al., 2016). Although low back pain has multiple etiologies, it is always associated with the nursing occupation worldwide (40-90\%). Hence, it is considered an occupational hazard (Qareeballa et al., 2018).

Low back pain has been documented as the major common reason of absenteeism among nursing staff (d'Errico et al., 2013). Nurses ranked the sixth highest with regard to nonattendance in the working days related to musculoskeletal disorders (Dhyani, Siddhartha \& Sen, 2015). They are the main hospital staff who always 
remain in close contacts with their patients. Nurses were found to report the highest level of work-related back pain. The main cause is showed to be the great amount of physical work involved in this profession, especially handling and transferring of patients, as well as jobrelated psychological stress. Persistent and continuous patient lifting, transferring and physical restrictions lead to physiological stress for nurses. Low back pain is thus considered an important health concern in nursing practices (Lela \& Frantz, 2012).

Pain stimulates sympathetic activation, also called fight-or-flight response which result in the release of stress hormone especially adrenaline and cortisol. Vital signs were also affected as blood pressure and heart rate increases (Jensen et al., 2012), respiration becomes shallow and its rate increases, the capillaries become contracted (Rohads, 2013).

Nowadays, both pharmacological and nonpharmacological methods are applied to relieve pain. Nursing researches attempted to find non-medicinal treatment methods to manage LBP due to the lack of long-term effectiveness of pharmacological therapy, and the side effects of analgesics (Tang et al., 2015). There are different types of non-pharmacological methods recommended; one of them is relaxation techniques (Pimentel et al., 2015).

Based on literature it can be said that relaxation techniques in general diminishes anxiety and musculoskeletal pressure (Zargarzadeh \& Memarian, 2013) and as a therapeutic strategy it has a positive effect on stressful and painful situations. Moreover, relaxation techniques are considered one of the most common methods used for different health problems. Moreover, relaxation decrease pain perception and tension, provide a pleasant mental state, decrease anxiety as a response to stress, activate parasympathetic system, increase concentration level, improve the sense of control, improve quality of sleep, reduce cardiac index, lower blood pressure, and finally enhance performance of physical and mental activities (Rohads, 2013). Relaxation techniques are varied and had different forms, one of them is jaw relaxation.

Jaw relaxation technique was first presented by Jacobson in 1938, focusing only on relaxing all speech organs at the same time. Moreover, it was found that Jaw relaxation technique used to relax the lips, throat and face showed a significant positive effect on alleviating pain level (Ellegaard \& Pederson, 2012). When the jaw tightens, the body reflexively tightens many muscles around the neck to provide proper support to the head and vertebral spine. It is sad to say that the result is neck and back tension followed by nerve pain. As the brain and vertebral spine are connected to each other, so relaxing the facial muscles and particularly jaw muscles will result in decreased pain sensation in the vertebral spine. Additionally, it is very effective in reducing muscle spasms, as well as improving circulation (Shwn et al., 2016). Moreover, this method was suggested to reduce pain through decreasing tissue's demand for oxygen, deteriorating chemicals levels (e.g., lactic acid), relieving tension of musculoskeletal system, and enhancing the release of endorphin (Zhou et al., 2015).

Jaw relaxation technique is increasingly recommended as an effective pain control measure that can be used by nurses in their daily practice (Felix et al., 2018). Moreover, practicing jaw relaxation technique for about 10 minutes before starting their work will have a significant impact on their performance (Doolen, Fenj \& Menzel, 2016). Therefore, the aim of the present study was to examine the effect of jaw relaxation technique on low back pain and selected vital signs among nursing staff.

\section{Significance}

It was observed during the clinical supervision of nurses at the selected hospital that the majority of nursing staff who worked in different settings were complaining of low back pain with various qualities. Many studies were done worldwide regarding jobrelated back pain in nursing which was found to be one of the most vulnerable occupations in which low back pain is concerned. Low back pain can directly affect nurses' productivity at work and consequently decreases the overall quality of health care provided to their patients.

Consequently, attention to alternative medicine to alleviate back pain is of great importance; accordingly, attention was directed toward relaxation technique as an effective non-pharmacological treatment therapy. There are different types of relaxation techniques; one of them is jaw relaxation. It is considered as one of most effective non-pharmacological method of pain control 
used to distract pain and reduce its effect. So, this study will allow nursing staff to manage their low back pain and reduce its severity by utilizing simple, safe, noninvasive, cost-effective, and self-administered method like jaw relaxation technique, which would contribute to lower back pain in their profession. It would have also great influence on reducing elevated pulse and respiratory rates as well as systolic and diastolic blood pressure resulted from low back pain. So the current research will help to reestablish the importance of improving low back pain through the practice of jaw relaxation technique as a nonpharmacological treatment measure.

\section{RESEARCH METHODOLOGY}

\section{Aim of the Study}

The aim of the present study was to examine the effect of jaw relaxation technique on low back pain and selected vital signs among nursing staff.

\section{Study Design}

A randomized control clinical trial design was utilized.

\section{Sample}

The sample size was determined by using the following equation (Charan \& Biswas, 2013):

$$
\mathrm{n}=\frac{\left(z \frac{\alpha}{2}+z_{\beta}\right)^{2}\left(P_{1}(1-P)+\left(P_{2}\left(1-P_{2}\right)\right.\right.}{\left(P_{1}-P_{2}\right)^{2}}
$$

$\mathrm{n}=$ sample size

$\mathrm{Z} \alpha / 2=$ the value for a type I error of $5 \%$.

$\mathrm{Z} \beta=$ the value for a type II error of $20 \%$.

$\mathrm{P}_{1}=$ proportion of nurses who practice jaw relaxation technique and developed low back pain $=32 \%$ (Panahi et al., 2012).

$\mathrm{P}_{2}=$ Prevalence of nurses who didn't practice jaw relaxation technique and developed low back pain $=$ 45\% (Panahi et al., 2012).

$\mathrm{P}_{1}-\mathrm{P}_{2}=$ effect size

The calculated sample size is 50 nurses, by adding $10 \%$ dropout; the required sample size will be 55 nurses. It means that the required sample size must be not less than 55 nurses with low back pain. The study population consisted of all nurses in the all medical wards and its specialty (nine wards) and all surgical wards and its specialty (thirteen wards) present in the selected governmental hospital. To apply the randomization, the block randomization technique was utilized (Kim \& Shin, 2014), to determine the wards where the study will be conducted. A total of five medical wards and its specialties as well as eight surgical wards and its specialties were required. Therefore, all nurses working in the selected wards were chosen following inclusion criteria as ault male and female nurses, with low back pain as they rated themselves in the numeric pain rating scale at " 1 "or more, had full time work (>36h/week), working for past 2 consecutive years, and agree to participate in the study, were invited to participate in the current research. While exclusion criteria include: have been absent for more than 6 months during the past 2 years, having any musculoskeletal or rheumatologic disorders, were currently or recently pregnant, has disc, herniation, trauma, major past surgery. Nurses who toke analgesics two hours before practicing the technique and those who complained of hypotension, bradycardia, and bradypnea were also excluded from the study.

\section{Sample flow chart}

Total invited randomized nurses met the inclusion criteria $=72$

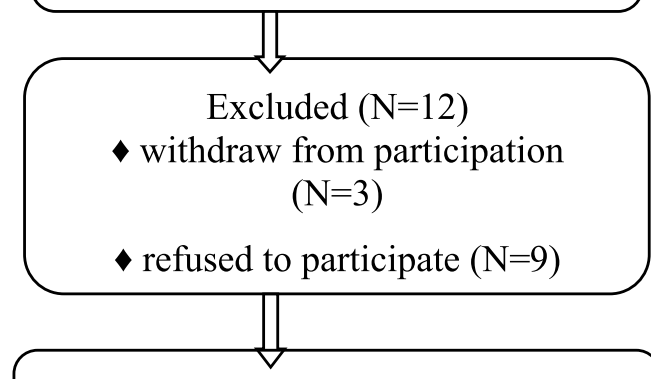

60 nurses were accepted to participate with response rate about $83.3 \%$

\section{Research Setting}

The study was conducted at five medical specialty departments (dialysis unit, two general medical wards, diabetic unit, and neurology ward) and six surgical 
specialty departments (Operating Room, orthopedic, recovery, urology, and two general surgical wards) in a governmental hospital in Egypt.

\section{Pilot study}

Pilot study was conducted at the beginning of the study. It was carried out on $10 \%$ (5 nurses) of the required study sample to assess the feasibility of the study and test tools for required time of filling out. Sample that were included in the pilot study was excluded from the study results. The result of the pilot study confirmed that the study was feasible.

\section{Ethical Considerations}

Official permission for data collection was obtained from the heads of the departments. Ethical considerations performed in the current research include the following: (1) Participation in the study is entirely voluntary as well as withdrawal from the study was allowed, (2) Confidentiality of the nurses through anonymity, (3) Nurses participated in the study voluntarily, (4) Verbal explanation of the nature and the aim of the study were done, and (5) Informed consent obtained. For ethical reason, there was no control group whereas, all the study sample received the same research intervention (jaw relaxation technique).

\section{Tools of data collection}

\section{Three tools were used for data collection:}

I. Demographic- and Work-Related Data: It was developed by the researchers. This tool was classified into two main sections. First section included personal data as: name, age, gender, marital status, income, and place of residence. Second section included data related to number of shifts/week, total work hours/ week and work place.

II. Numeric Pain Rating Scale (NPRS): It was a valid tool to measure perceptions of pain intensity, using a scale of 0 (no pain) -10 (worst pain imaginable), whereas " 0 " score indicate no pain, "1-3" scores indicate mild pain, "4-6" scores indicate moderate pain, while "7-10" scores indicate severe pain. This scale has been found to be reliable as well as easy and convenient to use $(\mathrm{r}=0.96)($ Hawker et al., 2011).
III. Medical Related Data: It included data related to selected vital signs particularly: respiratory rate (RR), heart rate (HR) and blood pressure (BP); as well as body mass index (BMI).

\section{Procedure}

The study had three phases to accomplish, which were:

Assessment phase: The researchers screened nurses in the selected wards and those who met the inclusion criteria were asked to rate their low back pain using the NPRS. Patients were asked to rate their low back pain three times, particularly the current, best, and worst pain experienced during the past 24 hours. The mean of these three ratings was utilized to represent patients' low back pain level. Then, the researchers explained the objectives, and the nature of the study to them, consent form was taken from nurses who agreed to participate. Demographic characteristics as well as medical data were assessed as base line information. Weight in kilograms and height in meters were measured, and then BMI was calculated, classified, and recorded for each nurse. Systolic and diastolic blood pressure as well as respiratory and heart rates were also measured immediately before practicing jaw relaxation technique.

Intervention phase: In this phase, the researchers started to apply the jaw relaxation technique (intervention practice) to the studied nurses. Studied nurses were approached individually in a selected quiet calm environment. The nurses were encouraged to assume a comfortable position while performing the practice and the researchers ensure that the nurse was not interrupted. The practice was started by taking deep breath for 5 minutes, followed by jaw relaxation practice for 10 minutes. The researchers then asked the studied nurses to return demonstration for one more round to make sure that all nurses could practice it correctly. Nurses were asked to practice the technique every day for ten minutes before the beginning of each shift, and they were followed up for one week. Moreover, nurses were provided with illustrated brochures and video related to the steps of jaw relaxation technique for practice whenever they want. Data was collected within two months. 
The steps of jaw relaxation technique (Soleimani, 2015).

\begin{tabular}{|l|}
\hline \multicolumn{1}{|c|}{ Steps } \\
\hline 1. Open the mouth as wide as \\
possible (without hurt), use \\
the left hand to slowly push \\
on the left side of the jaw. \\
Keep on this position for 10 \\
seconds then return to the \\
middle. Repeat on the other \\
side.
\end{tabular}

3. Put the thumb below the
chin. Open the mouth
gradually during do gentle
force from the bottom. Keep
the mouth open for 3-6
seconds. Repeat 3-6 times.

4. Open the mouth as wide as possible without causing any hurt. Then close the mouth. Repeat for 2 times.

5. Put an object (pencil) that is about $1 / 2$ an inch thick between the teeth. Gently move the jaw from one side to another. Repeat it, until it's too easy, use a thicker object (marker).

6 . With the same object used in the preceding step, move the lower teeth forward till it is in front of the upper teeth. Repeat it until it becomes easier.

7. Open the mouth and wide as possible and place the tip of the tongue to the roof of the mouth. Gradually performing pressure, move the tip of the tongue towards the tonsils and keep it there for 5 seconds. Repeat 5-10 times.
Evaluation phase: Following the interventional phase, studied nurses were assessed two times post intervention (after practicing jaw relaxation technique). The 1st post intervention assessment was done in the day of the initial interview immediately after practicing the technique, and the $2^{\text {nd }}$ post intervention assessment was done after one week from the initial interview. Evaluation was done for low back pain using NPRS, systolic and diastolic blood pressure, as well as respiratory and heart rates.

\section{Statistical Analysis}

The data was collected, organized, revised, tabulated and analyzed using the SPSS Version (2.0). Descriptive statistics was expressed as mean $\pm \mathrm{SD}$, as well as frequency and percentage distribution. Statistical $t$-test has been used to determine the statistical significant differences at pre and post intervention, and ANOVA test was used to compare more than two groups. Additionally, $r$-test was used to assess relationships between quantitative variables. Statistical significance was considered at $p$-value $\leq 0.05$.

\section{RESULTS}

Section I: Description of Demographic Characteristics, Work-Related Data and BMI among Nursing Staff

Table 1: Frequency and Percentage Distribution of Demographic Characteristics among the Study Sample $(n=60)$

\begin{tabular}{|l|c|c|}
\hline \multicolumn{1}{|c|}{ Variables } & No. & \% \\
\hline Age & \multicolumn{2}{|c|}{} \\
$-25-<30$ & 26 & 43.3 \\
$-30-<35$ & 24 & 40 \\
$-35-<40$ & 7 & 11.7 \\
$-40-45$ & 3 & 5 \\
\hline Mean \pm SD & \multicolumn{2}{|c|}{$28.95 \pm 5.7$} \\
\hline Gender & 12 & 20 \\
- Male & 48 & 80 \\
- Female & 39 & 65 \\
\hline Marital status & 31 & 35 \\
- Single & \multicolumn{2}{|}{} \\
- Married & 19 & 31.7 \\
\hline Residence & 41 & 68.3 \\
- Rural & \\
- Urban &
\end{tabular}


Table 1, shows that $43.3 \%$ of the studied nurses had age ranged between 25 to less than 30 years, followed by $40 \%$ of them age ranged between 30 to less than 35 years old. Female gender was predominant, whereas $80 \%$ of the studied sample were females, additionally, $65 \%$ were single, and $68.3 \%$ of them residing in urban areas.

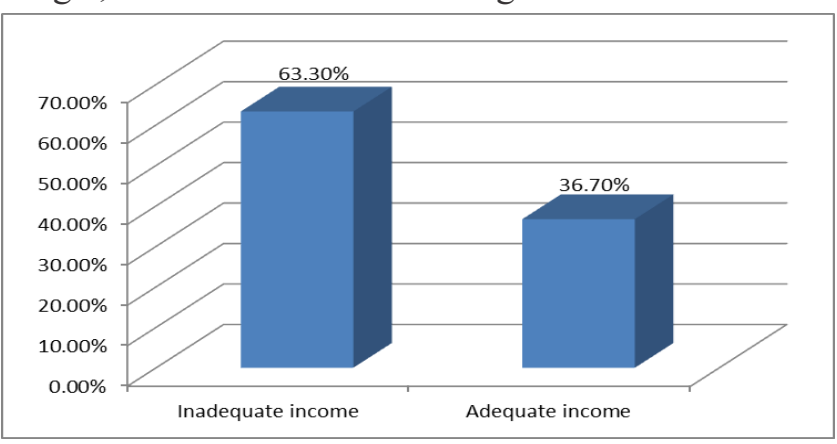

Figure 1: Percentage Distribution of Adequacy of Income as Reported by Nurses $(n=60)$

Figure 1 displays that $63.3 \%$ of the studied nurses reported that they had inadequate income.

Table 2: Frequency and Percentage Distribution of Work-related Data among the Study Sample $(n=60)$

\begin{tabular}{|l|c|c|}
\hline \multicolumn{1}{|c|}{ Variables } & No. & $\%$ \\
\hline Number of shifts/ weeks & & \\
- 3 shifts & 2 & 3.3 \\
- 4 shifts & 13 & 21.7 \\
- 5 shifts & 36 & 60 \\
- 6 shifts & 9 & 15 \\
\hline Total work hours / week & 11 & \\
- 30hrs - <36hrs & 39 & 18.3 \\
- 36hrs - <42hrs & 10 & 65 \\
- 42hrs - 48hrs & & 16.7 \\
\hline Work place & 21 & 35 \\
- Medical wards & 39 & 65 \\
- Surgical wards &
\end{tabular}

Table 2 shows that $60 \%$ of the studied sample had 5 shifts per week, with $65 \%$ of them worked for 36 to less than 42 hours per week, and in surgical wards.

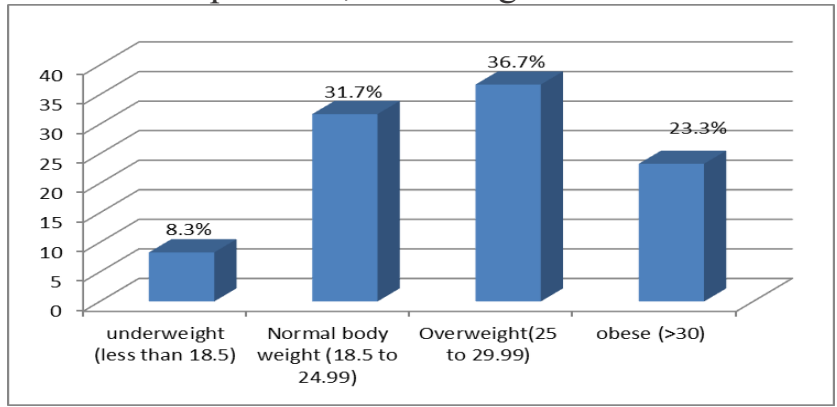

Figure 2: Percentage Distribution of Body Mass Index (BMI) among the Study Sample $(n=60)$
Figure 2 presents that the highest percentage $36.7 \%$ of the studied nurses were overweight, followed by $31.7 \%$ of them were with normal body weight.

Section II: Comparison of Means of Low Back Pain Scores Before and After Practicing Jaw Relaxation Technique as well as Relationship between Low Back Pain and both of Demographic Characteristics and Work-related Data

Table 3: Frequency and Percentage Distribution of Low Back Pain scores Before and After Practicing Jaw Relaxation Technique among the Study Sample $(n=60)$

\begin{tabular}{|l|c|c|c|c|c|c|}
\hline \multirow{2}{*}{$\begin{array}{c}\text { Low back pain } \\
\text { intensity score }\end{array}$} & \multicolumn{2}{|c|}{$\begin{array}{c}\text { Pefore } \\
\text { intervention }\end{array}$} & \multicolumn{2}{c|}{$\begin{array}{c}\text { Post } \\
\text { intervention } \\
\text { 1 } \\
\text { (Immediately) }\end{array}$} & \multicolumn{2}{c|}{$\begin{array}{c}\text { post } \\
\text { intervention } \\
2 \\
\text { (one week) }\end{array}$} \\
\cline { 2 - 7 } & No & $\%$ & No & $\%$ & No & $\%$ \\
\hline No pain (0) & 0 & 0 & 5 & 8.3 & 7 & 11.7 \\
Mild (1-3) & 10 & 16.7 & 37 & 61.7 & 36 & 60 \\
Moderate (4-6) & 26 & 43.3 & 15 & 25 & 15 & 25 \\
Severe (7-10) & 24 & 40 & 3 & 5 & 2 & 3.3 \\
\hline
\end{tabular}

Table 3, displays that $43.3 \%$ of the studied nurses had moderate low back pain intensity before intervention, while $61.7 \%$ and $60 \%$ of nurses reported mild low back pain during the period of post intervention 1 and post intervention 2 respectively.

Table 4: Comparison of Low Back Pain Mean Score Before and After Practicing Jaw Relaxation Technique among the Study Sample $(n=60)$

\begin{tabular}{|l|c|c|c|}
\hline \multirow{2}{*}{ Assessment Interval } & \multicolumn{3}{|c|}{ Low back pain intensity score } \\
\cline { 2 - 4 } & Mean + SD & $\boldsymbol{t}$-test & $\boldsymbol{p}$-value \\
\hline Before intervention & $5.6 \pm 1.9$ & 9.927 & $0.000^{*}$ \\
Post intervention 1 & $2.8 \pm 1.7$ & & \\
\hline Post intervention 1 & $2.8 \pm 1.7$ & 0.903 & 0.370 \\
Post intervention 2 & $2.7 \pm 1.5$ & & \\
\hline Before intervention & $5.6 \pm 1.9$ & 10.369 & $0.000^{*}$ \\
Post intervention 2 & $2.7 \pm 1.5$ & & \\
\hline$*$ p-value $<0.05$ & & & \\
\hline
\end{tabular}

Table 4 shows that there was a statistically significant difference in relation to low back pain mean scores before intervention versus post intervention 1 reading $(t$-test $=9.927, p$-value $=0.000)$, and post intervention 2 reading $(t$-test $=10.369, p$-value $=0.000)$. While, there was no statistically significant difference between post intervention 1 and post intervention 2 ( $t$ test $=0.903, p$-value $=0.370$ ). 
Table 5: Relationship between Low Back Pain Mean Score and Selected Demographic Data among the Study Sample $(n=60)$

\begin{tabular}{|l|c|c|c|c|}
\hline \multirow{2}{*}{ Variables } & \multicolumn{2}{|c|}{$\begin{array}{c}\text { Low back pain score } \\
\text { before intervention }\end{array}$} & \multicolumn{2}{c|}{$\begin{array}{c}\text { Low back pain score } \\
\text { after intervention }\end{array}$} \\
\cline { 2 - 5 } & test & $p$-value & test & $p$-value \\
\hline Age & $r=0.023$ & 0.863 & $r=0.020$ & 0.878 \\
\hline $\begin{array}{l}\text { Gender } \\
\text { Male }\end{array}$ & $t$-test $=3.1$ & & $t$-test $=4.13$ & \\
Female & $3.9 \pm 1.8$ & $0.003 *$ & $1.3 \pm 0.9$ & $0.000^{*}$ \\
\hline Marital & $5.8+1.9$ & & $3.4+1.6$ & \\
status & $t$-test $=0.8$ & & $t$-test $=0.64$ & \\
Single & & 0.398 & $2.8 \pm 1.6$ & 0.526 \\
Married & $5.6 \pm 2$ & & $3.1 \pm 1.9$ & \\
\hline * $p$-value $<0.05$ & $5.1 \pm 2.1$ & & \multicolumn{3}{|l}{} \\
\hline
\end{tabular}

Table 5 shows that there was a statistically significant difference between male and female gender in relation to low back pain mean score, either before intervention $(t$-test $=3.1, p$-value $=0.003)$ or after intervention $(t$-test $=4.13, p$-value $=0.000)$. Moreover, there was no correlation between age, marital status (single \& married), and low back pain mean score either before or after practicing jaw relaxation technique.

Table 6: Relationship between Low Back Pain Mean Score, Work-related Information and BMI among the Study Sample $(n=60)$

\begin{tabular}{|c|c|c|c|c|}
\hline \multirow[t]{2}{*}{ Variables } & \multicolumn{2}{|c|}{$\begin{array}{l}\text { Low back pain before } \\
\text { intervention }\end{array}$} & \multicolumn{2}{|c|}{$\begin{array}{c}\text { Low back pain } \\
\text { after intervention }\end{array}$} \\
\hline & test & $p$-value & test & $p$-value \\
\hline $\begin{array}{l}\text { Number of } \\
\text { shifts/ week }\end{array}$ & $F=0.223$ & 0.880 & $F=2.014$ & 0.122 \\
\hline $\begin{array}{l}\text { Total work } \\
\text { hours / week }\end{array}$ & $r=0.077$ & 0.557 & $r=0.044$ & 0.736 \\
\hline BMI & $r=0.054$ & 0.681 & $\mathrm{r}=-0.125$ & 0.340 \\
\hline Work place & $t$-test $=2.79$ & & $t$-test $=2.17$ & \\
\hline Medical wards & $4.38 \pm 1.9$ & $0.007^{*}$ & $2.52 \pm 1.2$ & $0.034^{*}$ \\
\hline Surgical wards & $5.64 \pm 1.4$ & & $3.38 \pm 1.5$ & \\
\hline
\end{tabular}

Table 6 presents that there was a statistically significant difference between nurses working in medical wards when compared to those in surgical wards in relation to low back pain mean score before intervention $(t$-test $=2.79, p$-value $=0.007)$ and after intervention $(t$-test $=2.17, p$-value $=0.034)$. Additionally, there were no correlations between number of shifts per week, total work hours per week and BMI in one hand and low back pain mean scores on the other hand.
Section III: Comparison of Means of the Selected Vital Signs Before and After Practicing Jaw Relaxation Technique

Table 7: Comparison of Selected Vital Signs Mean Scores before and after Practicing Jaw Relaxation Technique among the study sample $(n=60)$

\begin{tabular}{|l|c|c|c|c|}
\hline \multicolumn{1}{|c|}{$\begin{array}{c}\text { Inssessment } \\
\text { Interval }\end{array}$} & $\begin{array}{c}\text { Systolic } \\
\text { blood } \\
\text { pressure }\end{array}$ & $\begin{array}{c}\text { Diastolic } \\
\text { blood } \\
\text { pressure }\end{array}$ & $\begin{array}{c}\text { Heart } \\
\text { rate }\end{array}$ & Respiration \\
\hline Before intervention & $\begin{array}{c}123.7 \pm 16.3 \\
118.7 \pm 15.9\end{array}$ & $\begin{array}{c}78.3 \pm 8.4 \\
75.9 \pm 7.9\end{array}$ & $\begin{array}{c}85.6 \pm 9.4 \\
83.6 \pm 10.3\end{array}$ & $\begin{array}{c}19.5 \pm 2.8 \\
18.6 \pm 2.2\end{array}$ \\
\hline $\boldsymbol{t}$-test & 4.19 & 1.99 & 2.05 & 2.42 \\
p-value & $0.000^{*}$ & $0.051^{*}$ & $0.045^{*}$ & $0.018^{*}$ \\
\hline Post intervention 1 & $118.7 \pm 15.9$ & $75.9 \pm 7.9$ & $83.6 \pm 10.3$ & $18.6 \pm 2.2$ \\
Post intervention 2 & $116.9 \pm 16.5$ & $75.6 \pm 8$ & $83.5 \pm 10$ & $18.3 \pm 2.1$ \\
\hline $\boldsymbol{t}$-test & 0.61 & 1.907 & 1.271 & 1.704 \\
p-value & 0.081 & 0.061 & 0.209 & 0.094 \\
\hline Before intervention & $123.7 \pm 16.3$ & $78.3 \pm 8.4$ & $85.6 \pm 9.4$ & $19.5 \pm 2.8$ \\
Post intervention 2 & $116.9 \pm 16.5$ & $75.6 \pm 8$ & $83.5 \pm 10$ & $18.3 \pm 2.1$ \\
\hline $\boldsymbol{t}$-test & 4.366 & 2.245 & 2.141 & 3.292 \\
$\boldsymbol{p}$-value & $0.000^{*}$ & $0.029 *$ & $0.036^{*}$ & $0.002^{*}$ \\
\hline
\end{tabular}

Regarding systolic blood pressure, table 7, shows that there was statistically significant difference before practicing jaw relaxation technique and both post intervention $1(t$-test $=4.19, p$-value $=0.000)$, and post intervention $2(t$-test $=4.366, p$-value $=0.000)$. Additionally, there was statistically significant difference in diastolic blood pressure before intervention and post intervention $1(t$-test $=1.99, p$ value $=0.051)$, and between before intervention and post intervention $2(t$-test $=2.245, p$-value $=0.029)$. In relation to heart rate, there was a statistically significant difference between before intervention and both in post intervention $1(t$-test $=2.05, p$-value $=0.045)$, and post intervention $2(t$-test $=2.141, p$-value $=0.036)$. In addition, there was a statistically significant difference between before intervention and in both post intervention $1(t$-test $=2.42, p$-value $=0.018)$, and intervention $2(t$-test $=3.2 .92, p$-value $=0.002)$ regarding respiration. Moreover, there was no statistically significant difference between post intervention 1 and 2 , in relation to all selected vital signs.

\section{DISCUSSION}

Pain in soft tissues of the back is very common among adult nurses and frequently affects them within their working years. Results from the present study were presented in two main sections in which section (I) 
described the distribution of demographic characteristics of nurses and work-related information as well as BMI. Section (II) discussed the Comparison of low back pain mean scores before and after practicing jaw relaxation technique as well as relationship between low back pain and both of demographic characteristics and workrelated data. While section (III) demonstrated the comparison of means of selected vital signs (systolic and diastolic blood pressure, respiratory and heart rates) and low back pain mean scores before and after practicing jaw relaxation technique.

Regarding the first section, findings from the present study revealed that the highest percentage of nurses were females, with mean age of $28.95+5.7$, single, and residing in urban areas. In addition, about two thirds of them had inadequate income, and more than two thirds of them were overweight. Supporting these finding was the study conducted by Farooq et al., (2015), which showed that more than three quarters of their study sample were female nurses, and there was a slight significant association between low back pain and female gender.

It is commonly known that women are more likely to have low back pain at a specific time of their life, particularly during the pregnancy period. The increase in pregnancy hormones, having additional weight, and posture changes contribute to the having back pain. The current study showed contrary results in which two thirds of female subjects who complained from low back pain were single. This could be explained in the light of having other related problems such as obesity, lifting and bending, inappropriate posture, as well as spending long hours at work. This expectation which comes from researchers' point of view were supported by the current study findings, in which about two thirds of the study sample were either overweight or obese, and about two thirds of them had a total work hour ranged from 36-42 hours per week. Additionally, more than half of them had five shifts per week and worked in surgical wards.

Regarding low back pain assessment, it was found that, most of the nurses suffered from moderate to severe low back pain before practicing jaw relaxation technique, while after practicing it, about two thirds of them had mild pain. This result was explained in the light of the anatomical connection between facial muscles and vertebral column muscle, whereas, relaxation of jaw muscles will consequently lead to vertebral column relaxation which may lead to decrease intensity of low back pain.

Relaxation techniques are found to be effective as a non-pharmacological treatment strategy for painful and stressful conditions. Several studies have shown that relaxation technique reduces both sensory and emotional dimensions of pain (Chiou et al., 2013). In these studies, researchers examined the effect of jaw relaxation method and showed its effectiveness in almost all of them (Lin et al., 2012). These data supported the results from the present study in which statistically significant difference was found in low back pain mean scores before and after practicing jaw relaxation technique. This finding was expected from the researchers' side, as there was a significant reduction in systolic and diastolic blood pressure as well as in heart and respiratory rate after practicing jaw relaxation technique, which was considered indicators for reduced pain scores among the studied nurses. So there was statistically significant difference in low back pain intensity score after practicing jaw relaxation technique among nursing staff.

The study findings also revealed that there was a statistically significant difference between males and females regarding low back pain, whereas, females had higher low back pain mean score than males. The researchers may interpret this finding in the light of the cultural believes about femininity and masculinity, as pain expression is generally more socially accepted among females, while men are less willing to express pain. The results of the current study congruent with another study under title of "sex differences in pain: a brief review of clinical and experimental findings", which concluded that there were sex differences regarding pain whereas females had significantly increased pain sensitivity than male (Bartley \& Fillingim, 2013). Moreover, another study conducted in Nigeria has suggested that women developed chronic low back pain more than men. According to the results of this study, it was found that gene variant which promotes chronic back pain in women suppresses the same type of pain in men (Goel et al., 2015).

It was obvious in the current study that work setting had a significant impact on low back pain mean score rather than the number of shifts they had and the total shift hours per week, as nurses working in surgical wards had significant higher low back pain mean score than nurses working in medical wards. This could be 
explained that work in the surgical wards require lifting and transfer of patients. It was expected that most of the sample were young nurses so, they are always assigned to perform extra tasks and to take more shifts than senior nurses.

These findings highlighted the effect of type of activity variable especially bending and transferring activities carried out by nurses in these wards rather than length of time spent. Speaking in the same line was the study conducted by Abou El-Souda et al., in 2014, which showed that, the highest percentage of nurses' complains of low back pain associated with lifting heavy loads, followed by twisting, bending forward, prolonged standing, and walking for long distances. Another study conducted by Aljeesh \& Al Nawajha, in 2011, revealed that, nurses worked in hospital wards are often faced with a lot of unplanned work with various and numerous tasks, and responsibilities. Moreover, strong association was found between low back pain in nurses and their postures in physical work such as transferring patients and equipment and lifting of heavy objects (Shieh et al., 2016). Another study examining risk factors for low back pain among nurses showed that, workplace and employment factors such as seniority at the establishment, employment duration, and work shift hours per month had no significant effect on low back pain complaints among nurses (Vrbanić, 2011).

Results in section three, showed statistically significant difference before and after practicing jaw relaxation technique regarding selected vital signs as systolic and diastolic blood pressure as well as heart and respiratory rates which decreased in post intervention 1 and 2, when compared to pre-intervention interval. So there is statistically significant difference in selected vital signs after practicing jaw relaxation technique among nursing staff. This could be interpreted as, these selected vital signs are considered significant indicators for low back pain scores, when the pain intensity scores decreased, it was expected that, blood pressure, respiratory rate and heart rate dropped in turn. Another explanation could be possible is that practicing relaxation technique, also resulted in significant drop in blood pressure, respiratory rate and heart rate. Moreover, the literature confirmed that jaw relaxation technique resulted in a drop-in blood pressure, heart rate, as well as respiratory rate (Pi-Chu Lin, 2011). A similar study conducted to examine the effect of relaxation therapy revealed significant reduction in systolic and diastolic blood pressure in patients with elevated blood pressure (Soliman \& Mohamed, 2013). A recent study conducted to investigate the effect of relaxation technique on vital signs found significant lower rate of pulse, respiration and blood pressure in the experimental group when compared to control group (İbrahimoğlu \& Kanan, 2017).

In the current study, no statistically significant difference was found between post intervention 1 and 2 regarding low back pain mean score, as well as all the selected vital signs. This means that practicing jaw relaxation technique could have a constant same effect on both low back pain and selected vital signs, and its effect was not influenced by the frequency of performing the technique. As there was a minimal improvement observed in low back pain score in post intervention 2 than in post intervention 1, so a minimal non-significant effect was observed on selected vital signs. It is worth mentioning to say that hypothesis three was not supported. So, there is no statistically significant difference in low back pain intensity score and selected vital signs between post intervention $1 \& 2$.

\section{CONCLUSION}

The study findings revealed that the nurses suffered from moderate to severe LBP level before implementation of the jaw relaxation technique. While after the implementation of the intervention, the study sample improved significantly regarding LBP scores. Moreover, statistically significant difference was found regarding the selected vital signs before and after practicing jaw relaxation technique. While, no statistically significant differences were found between post intervention $1 \& 2$ in relation to LBP mean score and selected vital signs. So, by these findings; the study results supported two out of three research hypotheses.

\section{RECOMMENDATIONS}

\section{Based on the study results, the following recommendations were concluded:}

1. Jaw relaxation technique could be endorsed as an adjuvant pain management technique.

2. The study must be replicated on a larger study sample in different settings and for long intervals to generalize the results.

3. Further studies may be needed to determine the stability of the effect of the jaw relaxation technique on pain relief. 
4. Educational program must be established regarding the prevention and coping strategies for nurses to decrease the rate of work-related musculoskeletal disorders, including LBP, and competent patient care must be promoted.

\section{Nursing Implication}

Nursing is a uniquely hazardous occupation; nurses continue to report high levels of job-related injury and illness. The clear majority of nurses experience persistent job-related LBP. Therefore, it is worthy to find a way to relieve this pain. So, the endorsement of the jaw relaxation exercise as an adjuvant non-pharmacological LBP management technique for nurses in the routine day activity is crucial to help nurses to provide quality nursing care, especially, in work places that is characterized by heavy work such as surgical wards and medical wards.

\section{REFERENCES}

Abou El-Souda, A.M., El-Najjara A.R., El-Fattaha, A.N. \& Hassan, A.A. (2014). Prevalence of low back pain in working nurses in Zagazig University Hospitals: an epidemiological study. Egyptian Rheumatology \& Rehabilitation, 41(3), pp 109-115.

Aljeesh, Y. \& Al Nawajha, S. (2011). Determinants of low back pain among operating room nurses in Gaza Governmental Hospitals. Journal of Al Azhar University-Gaza (Natural Sciences), 13, pp 41-54.

Casas, S., Aminta, S., Patiño, S., María, S., Camargo, L. \& Diana, M. (2016). Association between the Sitting Posture and Back Pain in College Students. Revista de la Universidad Industrial de Santander. Salud, 48(4), pp 446-454.

Bartley, E. \& Fillingim, R. (2013). Sex Differences in Pain: A Brief Review of Clinical and Experimental Findings. British Journal of Anaesthesia, 111(1), pp 52-58.

Charan, J. \& Biswas, T. (2013). How to Calculate Sample Size for Different Study Designs in Medical Research? Indian Journal of Psychological Medicine, 35(2), pp 121-126.

Chiou, S.T., Chiang, J.H., Huang, N., Wu, C.H. \& Chien, L.Y. (2013). Health Issues among Nurses in Taiwanese Hospitals: National Survey. International Journal of Nursing Studies, 50(10), pp 1377-1384.

d'Errico, A., Viotti, S., Baratti, A., Mottura, B., Barocelli, A.P., Tagna, M., Sgambelluri, B., Battaglino, P. \& Converso, D. (2013). Low back pain and associated presenteeism among hospital nursing staff. Journal of Occupational Health, 55(4), 276-283.

Dhyani, D., Siddhartha, S. \& Sen, R. (2015). Effect of Progressive Muscular Relaxation on Stress and Disability in Subjects with Chronic Low Back Pain. IOSR Journal of Nursing and Health Science, 4(1), pp 40-45.

Doolen, J., Fenj, D. \& Menzel, N. (2016). Low Back Pain in Student Nurses: Literature Review and Prospective Cohort Study. International Journal of Nursing Education Scholarship.

Ellegaard, H. \& Pedersen, B.D. (2012). Stress is dominant in patients with depression man chronic low back pain. A qualitative study of psychotherapeutic interventions for patients with non-specific low back pain of 3--12months' duration. BMC Musculoskeletal Disorders, 13(166), pp 1471-2474.

Farooq, M.A., Awwal, L.M., Abdul Musa, H. \& Mustapha, G.A. (2015). Work-Related Risk Factors for Lower Back Pain Among Nurses In Ahmadu Bello University Teaching Hospital (ABUTH), Zaria - Nigeria. IOSR Journal of Nursing and Health Science, 4(3), pp 20-25.

Felix, M.M., Ferreira, M.G., Oliveira, F.L. \& Barichello, E. (2018). Guided imagery relaxation therapy on preoperative anxiety: a randomized clinical trial. Revista Latino-Americana de Enfermagem, 26, e3101.

Goel, S., Mani, P., Mangla, D. \& Goel, J.K. (2015). Low Back Ache in Working Women of Reproductive Age Group. Journal of South Asian Federation of Obestetrics and Gynaecology, 7(1), pp 33-36. 
Hanoch, K. \& Elavarasi, P. (2016). Definition of pain and classification of pain disorders. Journal of Advanced Clinical \& Research Insights, 3, pp 87-90.

Hawker, G.A., Mian, S., Kendzerska, T. \& French, M. (2011). Measures of adult pain: Visual Analog Scale for Pain (VAS Pain), Numeric Rating Scale for Pain (NRS Pain), McGill Pain Questionnaire (MPQ), Short-Form McGill Pain Questionnaire (SF-MPQ), Chronic Pain Grade Scale (CPGS), Short Form-36 Bodily Pain Scale (SF-36 BPS), and Measure of Intermittent and Constant Osteoarthritis Pain (ICOAP). Arthritis Care \& Research, 63 Suppl 11, S240-252.

İbrahimoğlu, O. \& Kanan, N. (2017). The Effect of Progressive Muscle Relaxation Exercises after Endotracheal Extubation on Vital Signs and Anxiety Level in Open Heart Surgery Patients. Türk Yoğun Bakım Dergisi, 15, pp 98-106.

Jensen, J.N., Holtermann, A., Clausen T., Mortensen, O.S., Carneiro, I.G. \& Andersen, L.L. (2012). The greatest risk for low-back pain among newly educated female health care workers; body weight or physical work load? BMC Musculoskeletal Disorders, 13:87.

Kim, J. \& Shin, W. (2014). How to do random allocation (randomization). Clinics in Orthopedic Surgery, 6(1), $103 \mathrm{e} 9$.

Lela, M. \& Frantz, J. (2012). The Relationship Between Low Back Pain and Physical Activity Among Nurses in Kanombe Military Hospital. AJPARS, 4(1 \& 2), pp 63-66.

Lin, P.H., Tsai, Y.A., Chen, W.C. \& Huang, S.F. (2012). Prevalence, characteristics, and work-related risk factors of low back pain among hospital nurses in Taiwan: A Cross-sectional survey. International Journal of Occupational Medicine and Environmental Health, 25, 41e50.

Merskey, H. \& Bogduk, N. (2017). "Part III: Pain Terms, A Current List with Definitions and Notes on Usage" (pp 209-214) Classification of Chronic Pain, Second Edition, IASP Task Force on Taxonomy. IASP Press, Seattle.

Panahi, Y., Saadat, A., Sahebkar, A., Hashemian, F., Taghikhani, M. \& Abolhasani, E. (2012). Effect of Ginger on Acute and Delayed Chemotherapy-Induced Nausea and Vomiting: A Pilot, Randomized, Open-Label Clinical Trial. Integrative Cancer Therapies, 11(3), pp 204-211.

Lin, P. (2011). An Evaluation of the Effectiveness of Relaxation Therapy for Patients Receiving Joint Replacement Surgery. Journal of Clinical Nursing, 21(5-6), pp 601-608.

Pimentel, C.B., Briesacher, B.A., Gurwitz, J.H., Rosen, A.B., Pimentel, M.T. \& Lapane, K.L. (2015). Pain management in nursing home residents with cancer. Journal of The American Geriatrics Society, 63(4), pp 633641.

Qareeballa, A.A. Alhamdan, O.A., Almutawaa, A.A., Alsayed, I.M., Kamal, F.A., Al Abdrabbuh, D.S., Al Suwaidi, M.K., Rashwan, M.A., Buhiji, A.M. \& Aref, B. (2018). Prevalence of Low Back Pain Among Female Nurses Working in Secondary and Tertiary Healthcare, Kingdom of Bahrain. International Journal of Medical Science and Public Health, 7(3), pp 183-187.

Rohads, C.J. (2013). Mechanism of Pain Relief Through Tai Chi and Qigong, Pain Relief. Journal of pain and Relief, 2(1), pp115.

Shieh, S.H., Sung, F.C., Su, C.H., Tsai, Y. \& Hsieh, V.C. (2016). Increased low back pain risk in nurses with high workload for patient care: A questionnaire survey. Taiwanese Journal of Obstetrics and Gynecology, 55(4), pp 525-529.

Soleimani, S. (2015). 8 Jaw Exercises to Relieve TMJ Pain. Retrieved from: https://www.sovanightguard. com/blog/8jaw-exercises-to-relieve-tmj-pain/ 
Soliman, H. \& Mohamed, S. (2013). Effects of Zikr Meditation and Jaw Relaxation on Postoperative Pain, Anxiety and Physiologic Response of Patients Undergoing Abdominal Surgery. Journal of Biology, Agriculture and Healthcare, 3(2), pp 23-38.

Tang, N.K., Lereya, S.T., Boulton, H., Miller, M.A., Wolke, D. \& Cappuccio, F.P. (2015). Nonpharmacological treatments of long-term painful conditions: A systematic review and meta-analysis of patient-reported outcomes in randomized controlled trials. Sleep, 38(11), pp 1751-1764.

Vrbanić, T.S. (2011). Low back pain - from definition to diagnosis. Reumatizam, 58(2), pp 105-107.

Zargarzadeh, M. \& Memarian, R. (2013). Assessing barriers for using of complementary medicine in relieving pain in patients by nurses. Iranian Journal of Nursing Vision, 1(4), pp 45-53.

Zhou, K., Li, X., Li, J., Liu, M., Dang, S., Wang, D. \& Xin, X. (2015). A clinical randomized controlled trial of music therapy and progressive muscle relaxation training in female breast cancer patients after radical mastectomy: Results on depression, anxiety and length of hospital stay. European Journal of Oncology Nursing, 19(1), pp 54-59. 